\title{
TAp73 is one of the genes responsible for the lack of response to chemotherapy depending on B-Raf mutational status
}

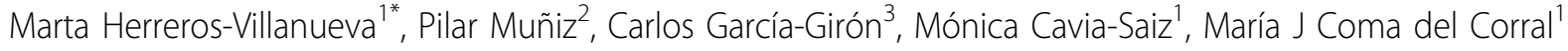

\begin{abstract}
Background: Although there have been many studies on the p73 gene, some of its functions still remain unclear. There is little research on the relationship between p73 gene transcription and its protein expression and the response to certain drugs such as oxaliplatin and cetuximab, which are drugs currently used in colorectal cancer. The purpose of this study was to evaluate the impact of TAp73 expression on oxaliplatin and cetuximab-based chemotherapy in colorectal cancer cell lines with different K-Ras and B-Raf mutational status.

Methods: TAp73 was analyzed in three colorectal tumor cell lines HT-29, SW-480 and Caco-2. mRNA TAp73 was determined using Real time PCR; TAp73 protein by immunoblotting and cell viability was analyzed by the MTT method.

Results: We found that mRNA and TAp73 protein were decreased in cells treated with oxaliplatin (in monotherapy or combined with cetuximab) when B-Raf is mutated. This was statistically significant and was also associated with higher cell viability after the treatment.

Conclusions: Here, for the first time we report, that there is a signaling loop between B-Raf activation and p73 function.

Low expression of TAp73 in colorectal cancer cell lines with mutated B-Raf may be involved in the lack of response to oxaliplatin in monotherapy or combined with cetuximab.
\end{abstract}

\section{Background}

The incidence of colorectal cancer has been increasing in the last few years, while the age of diagnosis is decreasing, and today it is the third or fourth cause of death in the world. The treatment of metastatic colorectal cancer (mCRC) has changed drastically since the 1980s, when only fluorouracil (5-FU) was available for treatment and the median survival was at the most 12 months, to a time when mCRC is considered more of a chronic disease in which the median survival is now reported to be in excess of 2 years, although the 5-year survival rate is still less than 10\% [1]. The advances in the treatment of this disease include studies of singleagents vs. combination treatment with 5-FU/leucovorin, irinotecan, oxaliplatin, and capecitabine, and the role of targeted agents such as cetuximab and bevacizumab.

\footnotetext{
* Correspondence: mhv@hgy.es

'Unidad de Investigación, Hospital General Yagüe, Burgos, Spain
}

The platinum-based chemotherapy drugs cisplatin, carboplatin, and oxaliplatin are among the most active and widely used agents for the treatment of colorectal cancer today [2]. Cisplatin is a third-generation platinum compound and like the rest of these agents, (oxaliplatin) kills tumor cells primarily by causing DNA damage [3].

Over the last few years, it has been reported that colorectal cancer is a polygenic disease in which oncogene mutation activation and tumor suppressor gene inactivation play important roles in the development of the disease and in the response to the chemotherapy.

\section{P73}

TP73 is a gene that was described by Kaghad et. al. in 1997 [4] and is a family member of the tumor suppressor gene TP53. TP53 and TP73 share significant structural and functional homology. Both genes contain an $\mathrm{NH}_{2}$ terminal transactivation domain, and a $\mathrm{COOH}-$ 
terminal oligomerization domain, and are capable of inducing cell cycle arrests and cell death in response to DNA damage. However, there is some evidence that shows that the roles of $p 53$ and $p 73$ in human tumor genesis are different.

P73 contains carboxy-terminal spliced variants known as the TA isoforms. The So-called $\Delta \mathrm{N}$ variants also exist, which lack the transactivation domain and are transcribed from an internal promoter within exon 3 of the full-length genes [5]. These different isoforms have been shown to have vastly different activities. The TA isoforms act similarly to p53, inducing apoptosis. In comparison, $\Delta \mathrm{N}$ isoforms have little transactivation activity and play a role blocking target genes of $p 53$ and their respective TAp73 isoforms [6]. Therefore, the TA isoforms may be expected to have functions in tumor suppression while $\Delta \mathrm{N}$ isoforms might be oncogenic.

For the first time in 2006, Dominguez et al. demonstrated an association between upregulation of $\triangle T A p 73$ isoforms and poor prognosis in colorectal cancer, specifically advanced tumor stage, suggesting that they may be of practical clinical prognostic value [7]. Last year, some authors also demonstrated that high expression of TAp73 in colorectal cancer may be involved in the progression of colorectal cancer and may serve as a potential index to predict differentiation level and prognosis of colorectal cancer [8].

Although there are many reports concerning the $p 73$ gene, some of its functions remain unclear. Little research has been reported on the relationship between p73 gene transcription and its protein expression with the response to certain drugs such as oxaliplatin and cetuximab which are drugs currently used in colorectal cancer.

Epidermal Grown Factor Receptor (EGFR) is one of the most important cell membrane receptors expressed in normal cells [9]. The EGFR molecular structure includes an extra-cellular region, a transmembrane domain and a protein tyrosine kinase region [10]. Epidermal Grown Factor (EGF) is a natural ligand of EGFR.

EGFR is abnormally activated in many epithelial tumors and it is frequently over expressed in colon cancer, correlating with a poor response to treatment, disease progression and poor survival [11].

In the early 80 s the EGFR was pointed out as a potential target for cancer therapy [12] and two anti-EGFR strategies were adopted: monoclonal antibodies (Mabs), which bind the extracellular domain, interfering with the natural ligand, and low-molecular-weight tyrosine kinase inhibitors, which interfere with the tyrosine kinase domain [13]. Cetuximab is a chimeric monoclonal antibody antagonist for EGFR that binds to EGFR with high affinity and prevents the ligand from adopting the conformation for dimerization and activation [14-17].
The most important mediators in EGFR signaling are K-RAS and B-RAF kinase proteins. Mutations in these effectors have been found in various cancers $[18,19]$.

$K$-Ras and B-Raf mutations are found in up to $50 \%$ and $10 \%$, respectively of colon cancers and appear relatively early in the carcinogenesis pathway leading to constitutive activation of its proteins [20,21]. Upon activation, RAS recruits RAF protein to the cell membrane and binds it directly, activating RAF kinase. B-RAF is considered to be the principal RAF isoform linking Ras to MEK signaling.

Several studies have indicated that the presence of mutant K-Ras in colorectal cancer correlates with a poor prognosis [21-23] and is associated with lack of response to EGFR inhibitors such as cetuximab [24,25]. Wild type $K$-Ras status is currently required to administer cetuximab in monotherapy, or combined with other agents, as it has been demonstrated that this is necessary but not sufficient to confer sensitivity to Cetuximab [26]. Some authors have recently concluded that B-Raf wild-type is also required for response to cetuximab and could be used to select patients who are eligible for the treatment [27]. However, not all of the wild type $K$-Ras and $B$-Raf patients are responding to cetuximab.

Therefore, the identification of additional genetic determining factors of the action mechanism of EGFRtargeted therapies in colorectal cancers (CRCs) is important at least for two reasons. First, the understanding of the molecular basis of therapies could allow the rational design of alternative treatment strategies. Second, to prospectively identify patients who should not receive either treatment, this way avoiding their exposure to ineffective and expensive therapy.

As it is well known P73 cooperates with Ras in the activation of MAPK kinase signaling cascade [28], we investigated the relationships between TAp73 expression and $K$-Ras/B-Raf status as regards of the chemosensitivity. Currently there are no data published on the correlation between TAp73 and cetuximab. In an attempt to further characterize this complex pattern of expression in human colorectal cancer cell lines and to assess its role in response to chemotherapy, the purpose of this paper was to analyze TAp73 mRNA and TAp73 protein expression in colorectal cancer cell lines treated with cetuximab and oxaliplatin, using Real Time PCR and Western Blot to explore associations between $p 73$ expression and $K$-Ras/B-Raf status.

For the experimental model of our study, we chose three human colon cancer cell lines: HT-29, SW-480 and Caco-2. These enterocyte cell lines were derived from human primary colon adenocarcinomas and are established cell models for the study of the biology and drug treatment of cancer. These cells lines are different in K-RAS and B-RAF pathways, as HT-29 harbors the 
V600E B-Raf heterozygotic mutation [29], SW-480 which harbors $K$-Ras mutation and Caco-2 is $K$-Ras and $B$-Raf wild type.

The association between the expression of TAp73 and the presence/absence of $K$-Ras and B-Raf mutations in response to cetuximab supports their possible apoptotic function and helps to understand the action mechanism of this drug.

\section{Methods}

\section{Tumor cell lines and culture conditions}

HT-29, SW-480 and Caco-2 human colorectal carcinoma cell lines were obtained from American Tissue Culture Collection (ATCC). All tumor cell lines were maintained in Dulbecco's minimal essential medium (DMEM) supplemented with 5\% fetal bovine serum, 2 $\mathrm{mM}$ L-Glutamine, $100 \mathrm{U} / \mathrm{mL}$ penicillin and $100 \mathrm{mg} / \mathrm{ml}$ streptomycin. Cells were maintained at $37^{\circ} \mathrm{C}$ in a $5 \%$ $\mathrm{CO}_{2}$ incubator in monolayer culture to $75 \%$ to $90 \%$ confluence and detached using $0.05 \%$ trypsin-EDTA.

Cells were counted using trypan blue and were adjusted to the desired concentration for plating.

\section{Reagents and drugs}

Cetuximab (C225, Erbitux $\left.{ }^{\circ}\right)$ was purchased from Merck Serono and Oxaliplatin from Ratiopharm. DMSO vehicle control was included in all the experiments.

Cells were plated in $25 \mathrm{~cm}^{2}$ culture flasks (Becton Dickinson) at $7.5 \times 10^{5}$ cells per flask and incubated for 24 hours. After the cells were attached, Oxaliplatin, Cetuximab, both of them, or drug control were added at the concentrations indicated and incubated for 48 hours at $37^{\circ} \mathrm{C}$. The concentrations were $10 \mathrm{nM}$ Cetuximab (recommended concentration by Merck and the most used concentration used in the literature) and $5 \mu \mathrm{M}$ Oxaliplatin (also the most frequent concentration used in the literature).

\section{Cell-viability assay}

Cell growth was determined using a MTT assay as previously described [30]. Human colon cancer cells were cultured in a 96-well plate (Becton Dickinson) at density of 5 $\times 10^{4}$ cells per well. The cells were then treated with fixed concentrations of oxaliplatin, cetuximab or both drugs. After 24, 48 and $72 \mathrm{~h}$, the cells were treated with MTT (Sigma-Aldrich). Plates were incubated in the dark for $4 \mathrm{~h}$, and the absorbances were measured at $570 \mathrm{~nm}$ using a microtiter plate reader (Bio-Tek). To determine cell viability, percent viability was calculated as [(absorbance of drug-treated) sample/(control absorbance)] $\times 100$.

\section{RNA isolation and Real Time PCR analysis}

Total RNA was extracted with TRI reagent (Ambion) following the manufacturer's protocol. cDNA was prepared using SuperScript ${ }^{\mathrm{tw}}$ II First-Strand Synthesis System for RT-PCR (Invitrogen) according to the manufacturer's protocol. The sequences of the primers used for PCR were as follows: TAp73-Forward: 5'-GCACCACGTTTGAGCACCTCT-3'; TAp73-Reverse: 5'-GCAGATTGAACTGGGCCATGA-3'. The reference gene used to standardize expression results was Ubiquitin $C$ (UBC): UBC-Forward: 5'-ATTTGGGTCG CGGTTCTTG-3' and UBC-Reverse: 5'-TGCCTTGA CATTCTCGATGGT-3'. Set primers were all as described previously [31].

Real-time PCR was performed in a final reaction volume of $50 \mu$ l containing $25 \mu \mathrm{l}$ of $2 \times$ SYBR Universal PCR Master Mix (Applied Biosystems), $0.5 \mu \mathrm{M} / \mathrm{L}$ of each primer and $4 \mu \mathrm{l}$ of cDNA. PCR was performed in MicroAmp optical 96-well plates with optical adhesive covers (Applied Biosystems). Amplification and detection were performed with an ABI prism 7500 sequence detection system (Applied Biosystems). The amplification conditions were 2 minutes at $50^{\circ} \mathrm{C}$ and 10 minutes at $95^{\circ} \mathrm{C}$ for AmpliTaq Gold activation, followed by 40 cycles of 15 seconds at $95^{\circ} \mathrm{C}$ for denaturation and 1 minute at $60^{\circ} \mathrm{C}$ for annealing and extension. The specificity of each primer set was confirmed by melting curve analysis.

\section{Western Blot Analysis}

For protein analysis, $7.5 \times 10^{5}$ cells were seeded, and after treatment, harvested, washed in $1 \mathrm{ml}$ of cold PBS and lysed in EBC lysis buffer $(50 \mathrm{mM}$ Tris pH8, 120 $\mathrm{mM} \mathrm{NaCl}, 0.5 \%$ NP-40) supplemented with a cocktail of protease inhibitors (Roche). Immunoblots were performed as described previously [32] and incubated overnight at $4^{\circ} \mathrm{C}$ in the following primary antibodies: mouse anti-p73 Ab-2 and Ab-4 1:500 (Oncogene) and rabbit anti-actin AA20-33 1:5000 (Sigma-Aldrich). Membranes were incubated with the appropriate HRP-coupled secondary antibodies (Pierce) and the enhanced chemiluminescence was detected with Super Signal West-Pico Chemiluminescent Substrate from Pierce. The protein expression levels were measured in a GS800 densitometer and using Quantity-One 4.6.8 Analysis Software (Bio-Rad).

\section{Data analysis}

The mRNA levels expression was determined by relative quantification using the comparative threshold cycle method ( $2^{-\Delta \Delta C T}$ Method), described and validated previously [33-35] Each sample is run in quadruplicate and the cell assays were made in triplicate. We validated this assay analyzing several controls (Untreated cells and genomic DNA from Applied Biosystems). In addition a melting curve analysis was performed which resulted in single product specific melting temperatures as follows: UBC, $81.8^{\circ} \mathrm{C}$ and $\mathrm{TAp} 73,84.5^{\circ} \mathrm{C}$. No primers-dimers 
were generated during the applied 40 real-time PCR amplification cycles.

\section{Statistical Analysis}

Results are presented as means and standard deviation $(\mathrm{SD})$, and $\mathrm{P}<0.05$ was considered statistically significant. Statistical analysis was performed with SPSS 11.0 (SPSS, Chicago, IL) for Microsoft Windows XP (Redmond, WA). The paired Student t test (2-tailed) was used to compare the values between treated and untreated cells and Anova test to compare the values among the three lines of cells.

\section{Results}

We characterized HT-29, SW-480 and Caco- 2 cell lines according to their viability, mRNA and protein TAp73 expression. We evaluated the role of TAp73 in untreated and treated conditions in order to compare their behavior and correlate their gene expression profile changes with K-Ras and B-Raf status.

\section{Cell viability assay}

HT-29 was compared to SW-480 and Caco-2 regarding cell growth under normal conditions (only treated with vehicle drug) at 24, 48 and 72 hours and after treatment with oxaliplatin, cetuximab and both.
The viability percentage of the untreated cell lines at the time of 24, 48 and 72 hours are showed in Figure 1a and p-values in Additional File 1. In absence of the treatment, the percentage of viability at 72 hours of the cells HT-29 was higher than in SW-480 and Caco2. This result is correlated with B-Raf mutational status as HT-29 harbors V600E mutation while SW-480 (which harbours K-Ras mutation) and Caco-2 (K-Ras wild type) are B-Raf wild type. This data confirm that B-Raf could confer greater viability than a wild genotype in colorectal cancer cell lines.

The treatment at 24 hours only affects to the viability of Caco- 2 cells treated with oxaliplatin alone or plus cetuximab where we observed a significant decreased compared with the control group. In contrast, the treatment for 48 hours decreases the cell viability in all cell lines, being this decrease significative for the treatment with oxaliplatin alone or combined with cetuximab in the SW-480 and Caco-2 cells, and with cetuximab in monotherapy in the SW-480 (Figure 1b). After 72 hours, a decrease in the viability percentage was observed only when the cells were treated with oxaliplatin in monotherapy. No changes were observed in presence of cetuximab in monotherapy and the combination oxaliplatin only affect to the HT-29 and Caco-2 cells.
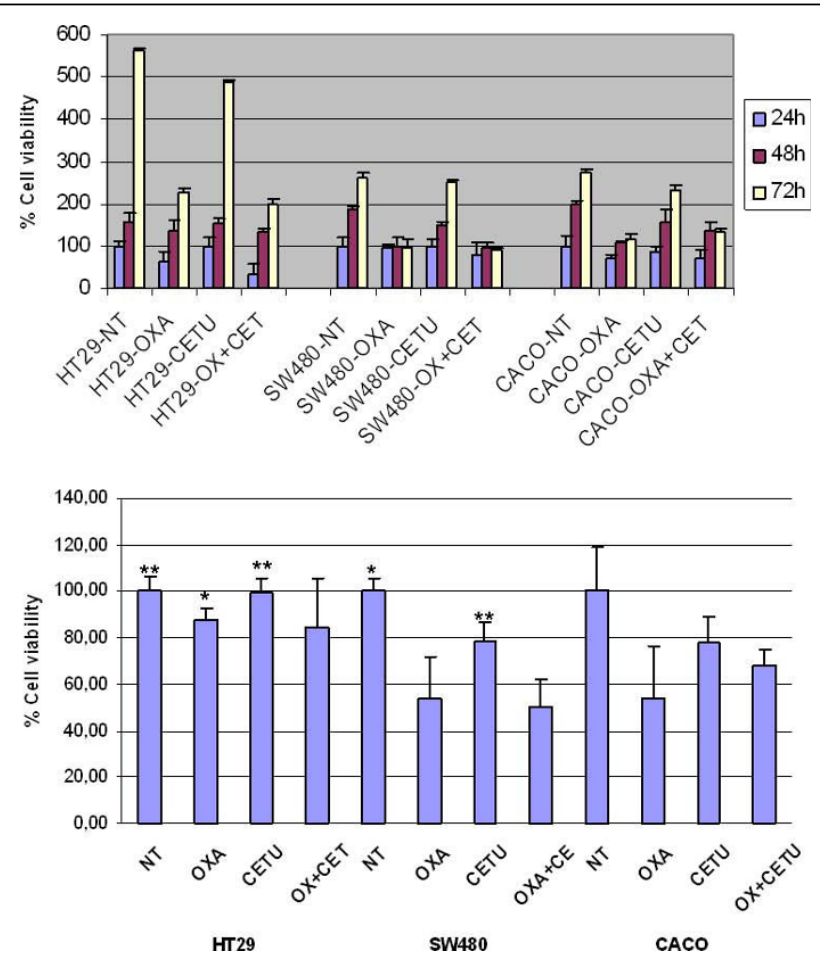

Figure 1 HT-29, SW-480 and Caco-2 viability assay. (A) Viability assay at 24, 48 and 72 hours. Untreated (NT), $5 \mu$ M Oxaliplatin (Oxa), 10 nM Cetuximab (Cetu) and $5 \mu \mathrm{M}$ Oxaliplatin plus $10 \mathrm{nM}$ Cetuximab (Oxa+Cetu). Cell grown was determined using a MTT assay. (B) Viability assay after 48 hours of treatment. T-Student analysis. ${ }^{*} P<0.05{ }^{*} P<0.01$. Each point represents a mean of triplicate values for each sample \pm SD. 
Table 1 Comparative study of the percentage of viability among Caco-2, SW-480 and HT-29 cell lines at different time of treatments.

\begin{tabular}{clllll}
\hline Time & Treatment & Caco-2 & SW-480 & HT-29 & P value \\
\hline $24 \mathrm{H}$ & NT & $0.72 \pm 0.07$ & $1.30 \pm 0.23$ & $0.80 \pm 0.17$ & 0.012 \\
\cline { 2 - 6 } & OXA & 0.510 .09 & $1.22 \pm 0.11$ & $0.58 \pm 0.05$ & $<0.001$ \\
\cline { 2 - 6 } & CETU & $0.67 \pm 0.12$ & $1.27 \pm 0.20$ & $0.59 \pm 0.16$ & 0.004 \\
\cline { 2 - 6 } & OXA+ CETU & $0.29 \pm 0.05$ & $1.03 \pm 0.28$ & $0.57 \pm 0.10$ & 0.006 \\
\hline $48 \mathrm{H}$ & NT & $1.29 \pm 0.24$ & $2.36 \pm 0.13$ & $1.22 \pm 0.07$ & $<0.001$ \\
\cline { 2 - 6 } & OXA & $0.73 \pm 0.15$ & $1.31 \pm 0.22$ & $1.08 \pm 0.05$ & 0.012 \\
\cline { 2 - 6 } & CETU & $1.03 \pm 0.11$ & $1.88 \pm 0.15$ & $1.28 \pm 0.41$ & 0.017 \\
\cline { 2 - 6 } & OXA+ CETU & $0.91 \pm 0.06$ & $1.32 \pm 0.13$ & $1.05 \pm 0.20$ & 0.032 \\
\hline $72 \mathrm{H}$ & NT & $3.48 \pm 0.02$ & $3.23 \pm 0.40$ & $2.02 \pm 0.11$ & 0.017 \\
\cline { 2 - 6 } & OXA & $1.44 \pm 0.13$ & $1.19 \pm 0.25$ & $0.89 \pm 0.07$ & 0.100 \\
\cline { 2 - 6 } & CETU & $3.03 \pm 0.15$ & $3.13 \pm 0.11$ & $2.43 \pm 0.31$ & 0.079 \\
\cline { 2 - 6 } & OXA+ CETU & $1.55 \pm 0.15$ & $1.26 \pm 0.03$ & $1.00 \pm 0.08$ & 0.025 \\
\hline
\end{tabular}

The treatment effect on viability percentage when comparing the different cell lines, is shown in Table 1. The result shows that there are significant changes among the three cell lines at 24 and 48 hours of treatment. However, at 72 hours we only observed significant differences in the untreated cells and treated with oxaliplatin plus cetuximab.

\section{mRNA TAp73 expression}

In order to investigate if the increase in cell viability associated to $K$-Ras and B-Raf mutation after the treatment was mediated by $p 73$, we analyzed the apoptotic TAp73 isoforms.

Relative quantification using Real Time PCR was performed to determine the influence of chemotherapy in mRNA TAp73 expression depending on the K-Ras and $B$-Raf status after 48 hours of treatment (Figure 2). pvalues are showed in Additional File 2.

This analysis showed us that in HT-29 cells, the treatment with oxaliplatin and oxaliplatin plus cetuximab dramatically decreased mRNA TAp73 levels. There were statistically significant differences between untreated cells and those treated with oxaliplatin in monotherapy or oxaliplatin plus cetuximab.

In comparison, in SW-480 and Caco- 2 cells treated with oxaliplatin in monotherapy or in combination with cetuximab, increasing mRNA TAp73 levels were observed. In these cells there were statistically significant differences between untreated cells and those treated with oxaliplatin and oxaliplatin plus cetuximab.

While, regardless of the $K$-Ras and $B$-Raf mutational status, cetuximab in monotherapy has no impact on mRNA TAp73 expression, oxaliplatin alone or in combination with cetuximab induces significant changes in TAp73. With these data, we believe that B-Raf mutational status may be one of the genes responsible for the changes in mRNA TAp73 expression levels. After treatment with oxaliplatin in monotherapy, or in combination with cetuximab, B-Raf mutation induces repression of mRNA TAp73.

\section{Protein TAp73 expression}

Immunoblot assays were performed to determine whether mRNA TAp73 levels were directly responsible for reduced or increased levels of TAp73 protein.

When measuring TAp73 by western blot and protein expression levels in a densitometer (Quantification values are showed in Additional File 3), it was observed that in untreated cells, Caco-2 expressed significantly higher $(\mathrm{p}<0.005)$ levels of TAp73 protein than SW-480 and HT-29 cells (Figure 3). These data suggest that TAp73 could be one of the many downstream RAS/ RAF/ERK proteins that could be modulating the apoptosis induced by chemotherapeutic agents, as when $K$-Ras and $B-R a f$ are wild type, cells are more sensitive to apoptosis induced by these drugs.

These findings could corroborate the data published by other authors showing that p73 is a determinant of chemotherapeutic efficacy in humans [36].

In HT-29 cells, it was found that after 48 hours, the treatment with oxaliplatin and oxaliplatin plus Cetuximab came out in a decreased TAp73 protein, reaching minimal levels (Figure 3). In this case, a direct correlation between mRNA and protein levels was obtained.

TAp73 protein levels were increased in SW-480 and Caco-2, when these cells were treated with cetuximab in monotherapy, and with oxaliplatin plus cetuximab. As the RT-PCR primers and antibody used were specific to TAp73, it is believed that cetuximab could induce a posttranscriptional regulation process in TAp73 expression.

The results of TAp73 protein expression after 72 hours of treatment were similar to those at 48 hours (data not shown).

When looking at oxaliplatin, it can be concluded that when B-Raf is wild type (regardless of K-Ras mutation), increased levels of p73 protein correlate enhanced TAp73 transcription, in the presence of cetuximab (cetuximab or cetuximab plus oxaliplatin).

When B-Raf is mutated, TAp73 mRNA levels correlate with reduced protein levels.

\section{Discussion}

P73 were cloned due to their structural similarity to $p 53$ and have been shown to share functions with the tumor suppressor gene $p 53$, but their contributions to the inhibition of tumor formation or to the response to chemotherapy has been uncertain. Many studies have revealed p53-like functions of TAp73, such as their ability to induce apoptosis, yet initial studies indicated that $p 73$ were not often mutated in human cancer [5]. 


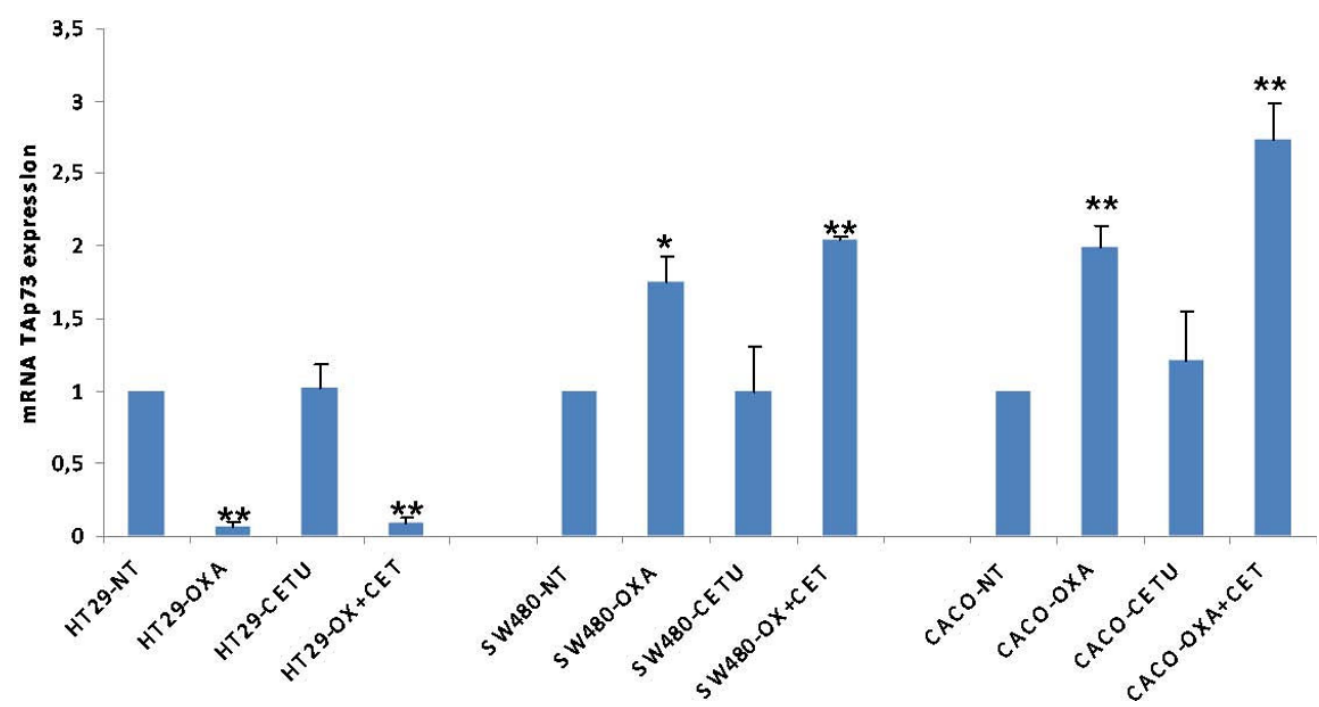

Figure 2 mRNA TAp73 expression after 48 hours of treatment. Untreated (NT), $5 \mu$ M Oxaliplatin (Oxa), 10 nM Cetuximab (Cetu) and $5 \mu M$ Oxaliplatin plus $10 \mathrm{nM}$ Cetuximab (Oxa+Cetu). T-Student analysis. ${ }^{*} P<0.05{ }^{* *} P<0.01$. Each point represents a mean of triplicate values for each sample \pm SD.

It is known that abnormal expression of $p 73$ gene plays an important role in the progression of colorectal cancer and its detection may be used to predict the prognosis of colorectal cancer and to guide treatment [8].

P73 has long been recognized as central to the induction of apoptosis in response to DNA damage, a function thought to be critical for tumor suppression and the response of tumor cells to chemotherapy agents [37].

Previous results suggest that p73 contributes to chemotherapy-induced apoptosis and support a model where p53 mutations induce chemoresistance, at least partly, through neutralization of p73 [36]. In this paper, we report for the first time that B-Raf mutations could also be increasing resistance to chemotherapy.

We explored the association of p73 expression levels as regards $K$-Ras and $B$-Raf status with the response to chemotherapy treatments in colorectal cancer cell lines.
Our results indicate that, regardless of K-Ras mutational status, TAp73 is induced by oxaliplatin (in monotherapy or in combination with cetuximab) when B-Raf is wild type. On the contrary, $B-R a f$ mutations inhibit the transcriptional activation of TAp73 induced after oxaliplatin treatment.

We came to the conclusion that if TAp73 is regulated differently depending on the $B$-Raf status, this could be a good reason for the lack of response to chemotherapy when $B$-Raf is mutated. When $B-R a f$ is mutated, the cells showed higher viability than $B$-Raf wild type cells. These data confirm that $B-R a f$ mutations could confer a more aggressive tumorigenic phenotype than $K$-Ras while it could be inducing chemoresistance. We also observed that $K$-Ras mutation confers greater viability than a wild genotype in colorectal cell lines.

In our model it was difficult to correlate the TAp73 gene expression profile and protein expression after

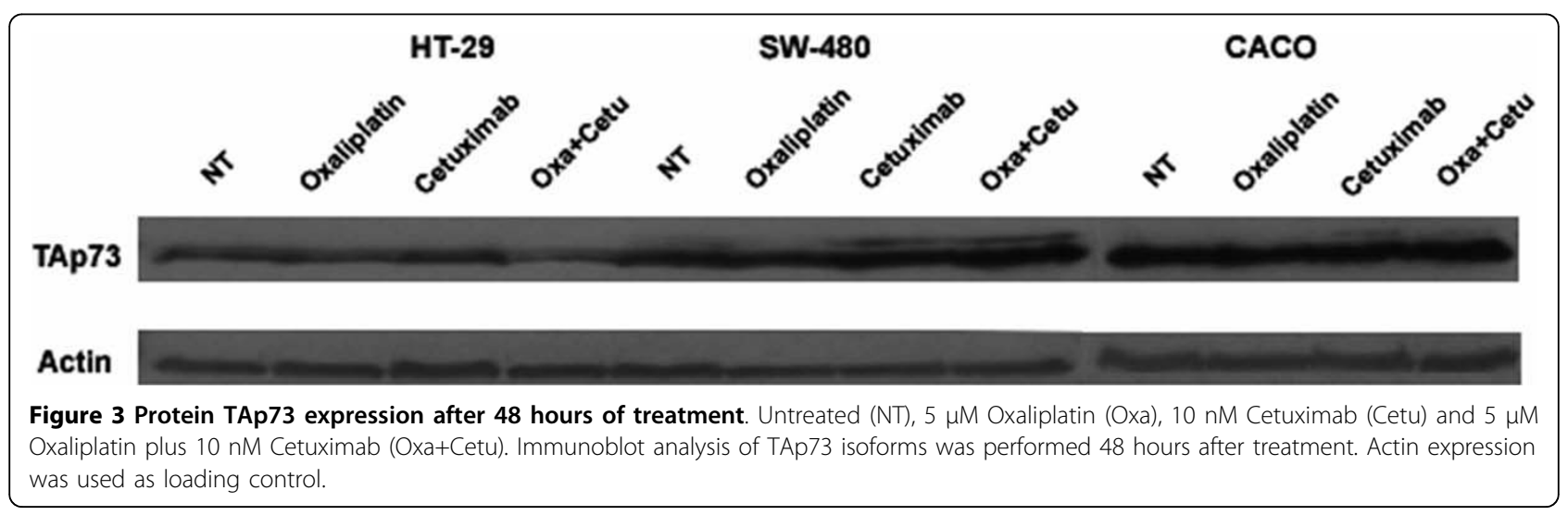


cetuximab treatment. We speculate that some p73 isoforms (TA or DN) could exert negative post-transcriptional effects leading to different mRNA stability in other p73 isoforms. Similar mechanism was described studing Myc regulation in neuroblastoma cells [38].

It is possible that the interaction between the family members and their isoforms may prove to be an extremely important aspect of chemotherapy response. In this sense, there is evidence that the interaction between p53, p73 and p63 may be involved in the response to this drug. Further experiments will be necessary to clarify this point.

In this case, we found a close correlation and specificity of mRNA TAp73 expression with the oxaliplatin and cetuximab response, suggesting that this method is useful to analyze the TAp73 profile dynamics.

\section{Conclusion}

Oxaliplatin in monotherapy or in combination with cetuximab produces an mRNA and protein TAp73 regulation effect. This effect is different depending on $K$-Ras and $B$-Raf mutational status, as we observed in HT-29, SW-480 and Caco-2 models.

When $B$-Raf is mutated, oxaliplatin induces TAp73 downregulation, while when $B-R a f$ is wild type, the treatment induces TAp73 upregulation. This induction is maintained when the treatment is combined with cetuximab.

We report, for the first time, that $B$-Raf mutations could confer a more aggressive tumorigenic phenotype than $K$-Ras, and could be inducing chemoresistance.

\section{List of Abbreviations}

B-Raf: V-raf murine sarcoma viral oncogene homolog B1; DMSO: Dimethyl sulphoxide; K-Ras: human homolog of the Kirsten rat sarcoma-2 virus oncogene; EGFR: Epidermal Grown Factor; EGFR: Epidermal Grown Factor Receptor; 5-FU: Fluorouracil; MTT: Thiazolyl Blue Tetrazolium Bromide; mCRC: metastatic colorectal cancer; TAp73: transcriptionally active p73.

\section{Conflicting interests}

The authors declare that they have no competing interests.

Additional file 1: $p$ values in viability assays. $P$ values corresponding to HT-29, SW-480 and Caco-2 after 24, 48 and 72 hours after treatment.

Related to Figure 1.

Click here for file

[http://www.biomedcentral.com/content/supplementary/1479-5876-8-15S1.XLS]
Additional file 2: $p$ values in mRNA TAp73 expression. $P$ values corresponding to mRNA TAp73 expression after 48 hours of treatment. Related to Figure 2.

Click here for file

[ http://www.biomedcentral.com/content/supplementary/1479-5876-8-15S2.XLS ]

Additional file 3: Protein expression levels. Arbitrary Units corresponding to the protein expression levels measured by densitometry.

Click here for file

[http://www.biomedcentral.com/content/supplementary/1479-5876-8-15S3.XLS]

\section{Acknowledgements}

We thank B. De La Nogal and the Pharmacy Department for their generous help. Also, we thank CMV and her group in Leon. This work was supported by a grant FIS CA08/00070 from Instituto de Salud Carlos III, Spanish Ministerio de Ciencia e Innovación to MHV and Fundación Burgos por la Investigación de la Salud. MHV is especially thankful to CVP, IHH and AHV, for their support.

\section{Author details}

'Unidad de Investigación, Hospital General Yagüe, Burgos, Spain.

${ }^{2}$ Departamento de Bioquímica, Universidad de Burgos, Burgos, Spain.

${ }^{3}$ Servicio de Oncología, Hospital General Yagüe, Burgos, Spain.

\section{Authors' contributions}

$\mathrm{MH}$ carried out experimental design and molecular genetic study and drafted the manuscript. PM participated in the design of the study and drafted the manuscript. CG carried out experimental design. MC carried out cell culture experiments. MJ participated in the study design and coordination. All the authors read and approved the final manuscript.

\section{Received: 18 August 2009}

Accepted: 10 February 2010 Published: 10 February 2010

\section{References}

1. Venook AP: Epidermal growth factor receptor-targeted treatment for advanced colorectal carcinoma. Cancer 2005, 103:2435-2446.

2. Kelland $L$ : The resurgence of platinum-based cancer chemotherapy. Nat Rev Cancer 2007, 7:573-584.

3. Donaldson KL, Goolsby GL, Wahl AF: Cytotoxicity of the anticancer agents cisplatin and taxol during cell proliferation and the cell cycle. Int J Cancer 1994, 57:847-855.

4. Kaghad M, Bonnet H, Yang A, Creancier L, Biscan JC, Valent A, Minty A, Chalon P, Lelias JM, Dumont X, Ferrara P, McKeon F, Caput D: Monoallelically expressed gene related to $p 53$ at $1 p 36$, a region frequently deleted in neuroblastoma and other human cancers. Cell 1997, 90:809-819.

5. Irwin MS, Kaelin WG Jr: Role of the newer p53 family proteins in malignancy. Apoptosis 2001, 6:17-29.

6. Yang A, Kaghad M, Caput D, McKeon F: On the shoulders of giants: p63, p73 and the rise of p53. Trends Genet 2002, 18:90-95.

7. Dominguez G, Garcia JM, Pena C, Silva J, Garcia V, Martinez L, Maximiano C, Gomez ME, Rivera JA, Garcia-Andrade C, Bonilla F: DeltaTAp73 upregulation correlates with poor prognosis in human tumors: putative in vivo network involving p73 isoforms, p53, and E2F-1.J Clin Oncol 2006, 24:805-815.

8. Sun XL, Ouyang XH, Yan MR, Liu GR: p73 expression and its clinical significance in colorectal cancer. Colorectal Dis 2008.

9. Hanahan D, Weinberg RA: The hallmarks of cancer. Cell 2000, 100:57-70.

10. Rowinsky EK: The erbB family: targets for therapeutic development against cancer and therapeutic strategies using monoclonal antibodies and tyrosine kinase inhibitors. Annu Rev Med 2004, 55:433-457.

11. Baselga J: Why the epidermal growth factor receptor? The rationale for cancer therapy. Oncologist 2002, 7(Suppl 4):2-8.

12. Mendelsohn J: Blockade of receptors for growth factors: an anticancer therapy-the fourth annual Joseph $\mathrm{H}$ Burchenal American Association of 
Cancer Research Clinical Research Award Lecture. Clin Cancer Res 2000, 6:747-753.

13. Matar P, Rojo F, Cassia R, Moreno-Bueno G, Di Cosimo S, Tabernero J, Guzman M, Rodriguez S, Arribas J, Palacios J, Baselga J: Combined epidermal growth factor receptor targeting with the tyrosine kinase inhibitor gefitinib (ZD1839) and the monoclonal antibody cetuximab (IMC-C225): superiority over single-agent receptor targeting. Clin Cancer Res 2004, 10:6487-6501.

14. Burgess AW, Cho HS, Eigenbrot C, Ferguson KM, Garrett TP, Leahy DJ, Lemmon MA, Sliwkowski MX, Ward CW, Yokoyama S: An open-and-shut case? Recent insights into the activation of EGF/ErbB receptors. Mol Cell 2003, 12:541-552.

15. Hubbard SR: EGF receptor inhibition: attacks on multiple fronts. Cancer Cell 2005, 7:287-288.

16. Li S, Schmitz KR, Jeffrey PD, Wiltzius JJ, Kussie P, Ferguson KM: Structural basis for inhibition of the epidermal growth factor receptor by cetuximab. Cancer Cell 2005, 7:301-311.

17. Scaltriti M, Baselga J: The epidermal growth factor receptor pathway: a model for targeted therapy. Clin Cancer Res 2006, 12:5268-5272.

18. Bardelli A, Velculescu VE: Mutational analysis of gene families in human cancer. Curr Opin Genet Dev 2005, 15:5-12.

19. Vogelstein B, Kinzler KW: Cancer genes and the pathways they control. Nat Med 2004, 10:789-799.

20. Servomaa K, Kiuru A, Kosma VM, Hirvikoski P, Rytomaa T: p53 and K-ras gene mutations in carcinoma of the rectum among Finnish women. $\mathrm{Mol}$ Pathol 2000, 53:24-30.

21. Andreyev HJ, Norman AR, Cunningham D, Oates J, Dix BR, lacopetta BJ, Young J, Walsh T, Ward R, Hawkins N, et al: Kirsten ras mutations in patients with colorectal cancer: the 'RASCAL II' study. Br J Cancer 2001, 85:692-696.

22. Esteller M, Gonzalez S, Risques RA, Marcuello E, Mangues R, Germa JR, Herman JG, Capella G, Peinado MA: K-ras and p16 aberrations confer poor prognosis in human colorectal cancer. J Clin Oncol 2001, 19:299-304.

23. Ince WL, Jubb AM, Holden SN, Holmgren EB, Tobin P, Sridhar M, Hurwitz HI, Kabbinavar F, Novotny WF, Hillan KJ, Koeppen H: Association of k-ras, braf, and p53 status with the treatment effect of bevacizumab. J Natl Cancer Inst 2005, 97:981-989.

24. Benvenuti S, Sartore-Bianchi A, Di Nicolantonio F, Zanon C, Moroni M, Veronese S, Siena S, Bardelli A: Oncogenic activation of the RAS/RAF signaling pathway impairs the response of metastatic colorectal cancers to anti-epidermal growth factor receptor antibody therapies. Cancer Res 2007, 67:2643-2648.

25. Lievre A, Bachet JB, Le Corre D, Boige V, Landi B, Emile JF, Cote JF, Tomasic G, Penna C, Ducreux M, Rougier P, Penault-Llorca F, Laurent-Puig P: KRAS mutation status is predictive of response to cetuximab therapy in colorectal cancer. Cancer Res 2006, 66:3992-3995.

26. Amado RG, Wolf $M$, Peeters $M$, Van Cutsem E, Siena S, Freeman DJ, Juan $T$, Sikorski R, Suggs S, Radinsky R, Patterson SD, Chang DD: Wild-type KRAS is required for panitumumab efficacy in patients with metastatic colorectal cancer. J Clin Oncol 2008, 26:1626-1634.

27. Di Nicolantonio F, Martini M, Molinari F, Sartore-Bianchi A, Arena S, Saletti P, De Dosso S, Mazzucchelli L, Frattini M, Siena S, Bardelli A: Wild-type BRAF is required for response to panitumumab or cetuximab in metastatic colorectal cancer. J Clin Oncol 2008, 26:5705-5712.

28. Fernandez-Garcia B, Vaque JP, Herreros-Villanueva M, Marques-Garcia F, Castrillo F, Fernandez-Medarde A, Leon J, Marin MC: p73 cooperates with Ras in the activation of MAP kinase signaling cascade. Cell Death Differ 2007, 14:254-265.

29. Davies H, Bignell GR, Cox C, Stephens P, Edkins S, Clegg S, Teague J, Woffendin H, Garnett MJ, Bottomley W, Davis N, Dicks E, Ewing R, Floyd Y, Gray K, Hall S, Hawes R, Hughes J, Kosmidou V, Menzies A, Mould C, Parker A, Stevens C, Watt S, Hooper S, Wilson R, Jayatilake H, Gusterson BA, Cooper C, Shipley J, Hargrave D, Pritchard-Jones K, Maitland N, ChenevixTrench G, Riggins GJ, Bigner DD, Palmieri G, Cossu A, Flanagan A, Nicholson A, Ho JW, Leung SY, Yuen ST, Weber BL, Seigler HF, Darrow TL, Paterson H, Marais R, Marshall CJ, Wooster R, Stratton MR, Futreal PA: Mutations of the BRAF gene in human cancer. Nature 2002, 417:949-954

30. Morgan DM: Tetrazolium (MTT) assay for cellular viability and activity. Methods Mol Biol 1998, 79:179-183.

31. Concin N, Becker K, Slade N, Erster S, Mueller-Holzner E, Ulmer H, Daxenbichler G, Zeimet A, Zeillinger R, Marth C, Moll UM: Transdominant
DeltaTAp73 isoforms are frequently up-regulated in ovarian cancer. Evidence for their role as epigenetic p53 inhibitors in vivo. Cancer Res 2004, 64:2449-2460.

32. Marin MC, Jost CA, Irwin MS, DeCaprio JA, Caput D, Kaelin WG Jr: Viral oncoproteins discriminate between p53 and the p53 homolog p73. Mol Cell Biol 1998, 18:6316-6324.

33. Livak KJ, Schmittgen TD: Analysis of relative gene expression data using real-time quantitative PCR and the 2(-Delta Delta C(T)) Method. Methods 2001, 25:402-408.

34. Schmittgen TD, Livak KJ: Analyzing real-time PCR data by the comparative C(T) method. Nat Protoc 2008, 3:1101-1108.

35. Pfaffl MW: A new mathematical model for relative quantification in realtime RT-PCR. Nucleic Acids Res 2001, 29:e45.

36. Irwin MS, Kondo K, Marin MC, Cheng LS, Hahn WC, Kaelin WG Jr: Chemosensitivity linked to p73 function. Cancer Cell 2003, 3:403-410.

37. Flores ER, Tsai KY, Crowley D, Sengupta S, Yang A, McKeon F, Jacks T: p63 and $p 73$ are required for $p 53$-dependent apoptosis in response to DNA damage. Nature 2002, 416:560-564.

38. Horvilleur E, Bauer M, Goldschneider D, Mergui X, de la Motte A, Benard J, Douc-Rasy S, Cappellen D: p73alpha isoforms drive opposite transcriptional and post-transcriptional regulation of MYCN expression in neuroblastoma cells. Nucleic Acids Res 2008, 36:4222-4232.

doi:10.1186/1479-5876-8-15

Cite this article as: Herreros-Villanueva et al.: TAp73 is one of the genes responsible for the lack of response to chemotherapy depending on BRaf mutational status. Journal of Translational Medicine 2010 8:15.

\section{Submit your next manuscript to BioMed Central and take full advantage of:}

- Convenient online submission

- Thorough peer review

- No space constraints or color figure charges

- Immediate publication on acceptance

- Inclusion in PubMed, CAS, Scopus and Google Scholar

- Research which is freely available for redistribution

Submit your manuscript at www.biomedcentral.com/submit
C Biomed Central 